\title{
Sustainable Strategies to Alleviate the Impact of the Seasonal Employment Scheme on Labour Market and Private Sector Businesses: Evidence from a Low-Middle Income Economy in the Pacific
}

\section{Michael Yemoh, Vicky Yemoh}

Faculty of Business and Entrepreneurship and Faculty of Health Sciences, National University of Samoa, Apia, Samoa Email: Michael_yemoh@hotmail.com,Vicky_yemoh@hotmail.com

How to cite this paper: Yemoh, M., \& Yemoh, V. (2021). Sustainable Strategies to Alleviate the Impact of the Seasonal Employment Scheme on Labour Market and Private Sector Businesses: Evidence from a Low-Middle Income Economy in the Pacific. Journal of Human Resource and Sustainability Studies, 9, 622-629.

https://doi.org/10.4236/jhrss.2021.94039

Received: November 15, 2021

Accepted: December 25, 2021

Published: December 28, 2021

Copyright $\odot 2021$ by author(s) and Scientific Research Publishing Inc. This work is licensed under the Creative Commons Attribution International License (CC BY 4.0).

http://creativecommons.org/licenses/by/4.0/

\begin{abstract}
The Seasonal Employment Scheme (SES) has been running in the Asia-Pacific region by New Zealand and Australia since 2007. Its merit has increased in recent months and past year, particularly due to the impact Covid-19 has had on economies worldwide, including the high unemployment rate which has occurred in some economies in the region. The economic benefits from the scheme imply that most economies will continue running the scheme and may be open to ideas or suggestions, which could potentially increase their gains from the scheme. This paper follows research into the influence of the SES on the available pool of workers, specifically private businesses in a middle-income economy in the Pacific. It provides possible strategies which could assist in improving the operation and management of the scheme in a way that minimizes the losses felt by the drain of labour and provides suggestions on how to spread the gains from the scheme economy-wide.
\end{abstract}

\section{Keywords}

Pacific Labour Scheme, Private Sector Businesses, Seasonal Employment Scheme, Sustainable Strategy

\section{Introduction}

The Government of New Zealand in 2006 approved the Recognized Seasonal Employer (RSE) policy and commenced its operation in 2007 (Immigration, Government of New Zealand, 2021). This policy aimed to benefit migrants, their 
countries of origin and destination countries (Ramsamy et al., 2008). The initial focus was to provide low skilled human resource assistance and to help the receiving countries overcome seasonal labour shortages (Fatupaito et al., 2021). The participating countries for the Pacific Labour Scheme (PLS) and Seasonal Worker Programme (SWP) schemes have since been expanded to include Fiji, Kiribati, Nauru, Papua New Guinea, Samoa, Solomon Islands, Timor-Leste, Tonga, Tuvalu and Vanuatu (DFAT, 2019). This expansion provided RSE employers access to a consistent supply of labour. In the year ended 30 June 2017, 16,603 seasonal workers from nine Pacific countries $(14,727)$ and seven Asian countries (1876) arrived in Australia and New Zealand under the terms of the Seasonal Worker Program (6166) and the Recognised Seasonal Employer (RSE) Scheme $(10,437)$ (Bedford, Richard, \& Ingram, 2018). The annual cap of workers recruited through this route increased to 14,400 workers in 2019 , and had remained at that level for the 2020/21 season (Bedford Bedford, \& Nunns, 2020). Australia's Pacific Seasonal Worker Pilot Scheme (PSWPS) was announced in the lead up to the Pacific Islands Forum in August 2008. It was trialed over three years from February 2009 to June 2012 in the horticulture industry, initially being confined to Swan Hill-Robinvale in Victoria and then to Griffith in New South Wales (DFAT, 2019). The nature of the SWP and the PLS has recently changed to provide employment opportunities beyond agriculture (Bedford, Bedford, \& Nunns, 2020). The PLS employment with a meat processing focus, offers up to three-year work contract which is subject to workers providing signed consent forms from family members, stating their agreements to their family members being on the scheme. The scheme is open to both men and women between the ages of 21 and 40 years respectively. Applicants must be English literates with high levels of mobility, cardio and strength-tested fitness and should satisfy occupational health requirements and police clearance. For agricultural and horticultural work in Australia or New Zealand under the SWP and the RSE, contracts are up to seven months (RSE) and nine months (SWP), with similar selection criteria (Fatupaito et al., 2021).

The SWP in Australia and the RSE schemes in New Zealand are similar and are classified as the Seasonal Employment Scheme (Curtain et al., 2018). Both are highly regulated schemes for the employment of low-skilled migrant workers. A recent study reported that one of the participating Pacific Island countries was losing her most productive male labour force to the scheme. This is expected to threaten the country's local economic and social development (Bedford, Richard, \& Ingram, 2018).

The benefits of participating in the scheme include a superior remuneration package, which is much higher than the wages of some skilled workers in participating Pacific countries who are not on the scheme. This helps to reduce unemployment rates by providing a viable option to employ some unemployed nationals albeit overseas. It also increases the flow of remittance income to participating Pacific Island Countries and Territories (PICTs), thus increasing the money supply into the country. Additionally, there are Foreign Exchange gains, 
financial service gains and its associated benefits to households. Also, there is an increase in consumer spending from the increased money supply on building houses, buying cars, funding of small businesses and opportunities to have earnings remitted to households with little or no cash income (see Bedford, Bedford, \& Ho, 2009). The scheme's operation in the Pacific has also attracted some criticisms such as its potential labour market effects, its resemblance with the colonial labour trade and the creation of a new form of external dependency (Craven, 2015). Prior studies revealed that the scheme contributes to the shortage of available workforce especially of low paying employers and negatively impacts on private business operators from participating nations (Fatupaito et al., 2021). Work skills and the training provided to workers, in addition to work ethics instilled in the workers who have previously been trained by businesses prior to their employment under the scheme, are lost. This has resulted in disruption in production and services and in some cases to businesses. There is also loss of skills from trained seasonal workers who return to their home countries, where similar farms and industries are absent or the opportunities to deploy their new skills. Additionally, there is loss of employed labour force from the local pool of workforces due to the comparable competitive remuneration package on offer by the scheme. This understandably has caused a further drain on the availability of labour for domestic work and in certain cases may have had an impact on the loss of interest to work.

The scheme generally provides short-term limited financial impact to individuals within the economy instead of a harnessed long-term financial aggregate gain with a multiplier effect to the economy. Due to the regular supply of money into the economy, this may inadvertently be contributing to inflation. Moreover, oversea recruiters often request for the healthiest, strongest, quality, reliable and loyal workforce and therefore it is more economical and economical for them to keep requesting for the same workers, thus increasing the inequality in the economy. There is value in getting work under the scheme even if it takes a long time, meaning, those who get the opportunity want to hold on to them. Interestingly, the employment opportunities can remain within the same extended family or village groups, rather than spread to other non-participating households, as the scheme employers tend to use existing workers to recruit new workers. Similarly, some scheme employers allow inter-generational transfer of jobs within families and use that as a reward for experienced workers (Bedford, Bedford, \& Nunns, 2020).

In early 2021, Samoa's Minister for Labour stated that 3400 seasonal workers were engaged overseas. In 2019/2020, nearly USD $\$ 80,000,000$ had been earned by seasonal workers (Fatupaito et al., 2021). Economic benefits from the scheme imply that participating economies will continue running the scheme and may be open to ideas or suggestions which could potentially increase their gains. This paper presents strategies which could potentially assist in improving the operation and management of the scheme in an economically sustainable way. In most cases, the unique nature of the economy will mean adapting and modifying 
these strategies to make them applicable. This paper does not intend to provide an exhaustive solution to all problems. In most cases, adapting and tweaking the suggestions in an appropriate way may be necessary to make them effective.

\section{Sustainable Seasonal Employment Strategies}

The official defence of the intentions and purposes of the SES is to only engage and employ workers who are classified as unemployed or low skilled. As a result, most governments will not have any mitigating solutions for the impact the scheme may have on businesses whose employees are recruited under the scheme. In recent reports (Radio New Zealand, 2020), it had become apparent that not only are unemployed unskilled workers being recruited under the scheme, but in some cases employed skilled workers give up their current positions of employment for this opportunity. In most cases, employed skilled workers would have received some sort of training to equip them in the capacity in which they were employed prior to their recruitment under the scheme. Any losses from employment means there are losses of skills that have been invested in employees, especially when employees do not return to the same employment after their assignment overseas comes to an end.

The first important strategy will be for the government to recognize that employed skilled workers are becoming victims, too. Research into private businesses will aid governments to recognize the extent of the impact and how many local business operators are affected. A review of prior findings whilst exploring different ways on limiting the occurrences and the negative impact it is having on businesses and the economy may be necessary. From these, governments need to provide ways to assist affected businesses with assistance like recruitment support, mitigating their staff replacement costs, provide the affected businesses with free Human Resource (HR) training and other suitable response packages. Another option will be to claim back part of the earnings of the seasonal workers who were employed in those businesses to assist them navigate through their financial losses as a result of staff shortage.

A database of unemployed people looking for work who are ready to work may be created to provide a pool of replacement workers for affected businesses. Businesses who are affected by staff losses will be required to inform the government of their losses. From the confirmed report of their loss of staff to the scheme, they would be provided with trained workers from the pool of unemployed workers list. This will equip the previously unemployed workers with specific skills to take up the available opportunities. This also helps to increase the employment levels of the economy whilst assisting the businesses limit disruptions. An on-going review of the scheme, assessing its impact on the economy, businesses and skill shortage may be necessary to enhance the sustainability of the scheme.

Additionally, since some employees had acquired prior work skills before leaving to work under the scheme, it may be necessary to take records of the 
skills lost and provide trainings in those areas to individuals searching for employment. Countries like Australia, keeps records of skills that are available across various cities and regions. This ensures that employers replace any skill losses and guarantees optimum levels of skills in the economy. Many seasonal workers may not likely return to a comparatively lower remuneration level when there are still opportunities with the scheme to earn more. However, in cases where workers are unable to return to the scheme, this may be the reason why they may then consider returning to the local workforce after earning such higher levels of comparative income.

Based on the size, cash flow, debts and other factors under which businesses operate, the impact from losses of critical staff may be severe and could affect business operations. There is also cost in finding replacements and further investments in providing what is necessary to upskill or train existing workers as replacements.

No one can deny the fact that the SES may have caused financial stress on business operations and as such, reasonable financial adjustments and compensation may be essential. Strategic business adaptation adjustments to current contracts are necessary to support businesses that lose staff. These aids could be delivered through cash payments, specialised and specific training programs or recruitment supports and resource management. These could help in smoothening the effect of staff losses and could be funded by deductions from the workers' earnings.

One of the criticisms of the scheme is its ability to take employed workers. What could be happening may be slightly different from what the scheme was intended to do. The aim of the scheme may have been for the unemployed to be given the opportunity to work. However, what could be happening is that the number of unemployed individuals may remain the same, whilst the employed are exported overseas for work. Thus, the level of domestic unemployment remains significantly unchanged. Another strategy will be to adapt the enrolment screening process, to ensure that only verified unemployed participants are recruited. The recruitment agency for the scheme could devise a way to confirm if an applicant was currently employed or had been employed in the recent determined period. If the applicant was currently in employment or had recently been on the scheme, they must be excluded from the list to favour other unemployed applicants. Some ways to confirm if an applicant was currently in employment or had recently been on the scheme could be to request for bank statements for a determined period or check the contributions with the authorised agencies who manage superannuation and pension contributions for that country. Other creative and appropriate means used to verify work status and to confirm work-based payments may be required, thus, in cases where applicants had been engaged in cash-only payments for their past employments. A high degree of surveillance will be required to ensure it does not encourage more people to purposely choose to stay out of the workforce as a way of meeting the lack of work criteria for the scheme. Alternatively, putting a restriction on workers who 
have not contributed towards their superannuation in a period of three years or individuals who are registered as unemployed from a list of verified records could also be desirable. These important suggestions may make recruitment on the scheme easier in the long run.

As previously mentioned, some trained seasonal workers may find difficulties in returning to their country of origin to utilise the skills acquired. There is therefore the need to create facilities, farms and appropriate infrastructure in the sending countries to effectively redeploy the skills of returning seasonal workers. This will help sustain the skills imparted to workers from the scheme into the economy. Where the climate and other factors permit, the possibility of moving part or all scheme as development projects into the participating countries could be recommended. However, this is subject to both parties agreeing and emphasizing on retaining and multiplying the financial returns of the scheme. With this in place, workers will first be employed under the scheme in their home country which will in turn create local employment. This path could also reduce incidences of employed skilled citizens being lost to the scheme. At the end of the seasonal scheme assignment, not only will new jobs be created across both countries, but also the same farms or agricultural processing plants and skill investments provided to workers overseas will be transported into the domestic economy of participating countries. These projects could be built and funded through development aids and projects or from small deductions taken from the salaries who are given the opportunity to work seasonal workers.

A strategy that ensures more equitable distribution of opportunities and income across communities must be implemented, since some recruitment practices result in few workers benefiting and retaining the seasonal employment opportunity with the same village, family or circle. This unfortunately, is increasing the inequality and disparity of opportunities across the economy. A strategy that limits the number of seasons an RSE worker could return to the receiving countries to work and or introducing a temporal ban after a specified number of years of employment may help reduce economic disparities and limit the harm caused to rural communities from excessive loss of productive working-age labour (Bedford, Bedford, \& Nunns, 2020).

\section{Conclusion}

The Seasonal Employment Scheme presents various opportunities for workers which seem to fuel the rise in interest across the Asia-Pacific region. The scheme provides an opportunity for employees to work for a better comparative remuneration without the need to have a particular skill or education level, and the opportunity to fulfil an overwhelming desire to live outside their country or travel outside one's country. The scheme offers a comparatively higher pay incentive for making the same choice to work albeit in a different location. It also gives employees the opportunity to learn new skills and explore other options besides what they are used to. In some cases, it fits into the culture of making a 
lot of money quickly and presents the chance to make a difference in the family with respect to the regular financial commitments, loans, debt and other obligations. Thus, there is an attractive opportunity of having two jobs; one overseas which quickly becomes permanent and another job domestically. Overall, the SES besides the great individual benefits and other benefits has some criticisms including potential long-term losses to business sectors and whole industries, due to these organisations being unable to sufficiently attract and retain their best workers, no matter how much investments they put in them. As a result, strategic steps may be needed by providers of the workforce to ensure that the benefits of the scheme go beyond individual workers and the opportunities of the scheme are more spread to possible participants, whilst being harnessed in a way that broadens its effects and benefits.

Strategies postulated in this paper include creating commercialised industries, establishing similar agricultural farms in the participating countries that create jobs to redeploy the returning seasonal workers into similar skilled employment when they return to their countries of origin. The best amongst them could be employed in vocational training institutions to pass on their skills and expertise. Governments could also subsidise participating businesses with tax breaks and provide other assistance where necessary. Tightening of recruitment processes which protects and retains skilled labour may also be essential, as well as officially recognising and compensating private businesses that lose employed staff to the scheme. A possible retention of a portion of the earnings of seasonal workers can be used for building projects which could help with their redeployment and settlement.

\section{Limitation}

This research is limited in the fact that the strategies mentioned could make the already running scheme more sustainable and effective in reducing labour market shocks. These strategies are not tried and tested strategies specific to this concept, although quite a number of research papers had already been published on the scheme without possible strategies to tighten the scheme. Our suggestion for further research will be to select a bigger sample size of Pacific Island countries that are participating in the SES, who will then apply these strategies and comprehensively analyse results to confirm their effectiveness.

\section{Conflicts of Interest}

The authors declare no conflicts of interest regarding the publication of this paper.

\section{References}

Bedford, C., Bedford, R., \& Ho, E., (2009). The Social Impacts of Short-Term Migration for Employment: A Review of Recent Literature. Research Report for New Zealand Aid Programme. 
Bedford, C., Bedford, R., \& Nunns, H. (2020). RSE Impact Study: Pacific Stream Report. https://www.researchgate.net/publication/343893403 RSE Impact Study Pacific strea m report

Bedford, R., \& Ingram, R. (2018). Supply of Workers for Seasonal Employment in Australia and New Zealand: A Summary Analysis and Forecast to June 2021. Unpublished Report for Labour Mobility Assistance Program.

Craven, L. (2015). Migration-Affected Change and Vulnerability in Rural Vanuatu. Asia Pacific Viewpoint, 56, 223-236. https://doi.org/10.1111/apv.12066

Curtain, R., Dornan, M., Howes, S., \& Sherrell, H. (2018). Pacific Seasonal Workers: Learning from the Contrasting Temporary Migration Outcomes in Australian and New Zealand Horticulture. Discussion Paper No. 65, Development Policy Centre. https://doi.org/10.2139/ssrn.3076585

DFAT (Department of Foreign Affairs and Trade) (2019). Pacific Labour Scheme (PLS), Policy Handbook. Department of Foreign Affairs and Trade. https://www.dfat.gov.au/geo/pacific/engagement/pacific-labour-mobility

Fatupaito, A. A., Utuva, L. S. J., Tauave, S. E., Alofipo, A. S., Meleisea, M., Schoeffel, P. et al. (2021). Samoa's New Labour Trade. Journal of Samoan Studies, 11, 51-61. https://journal.samoanstudies.ws/2021/10/29/samoas-new-labour-trade/

Immigration, Government of New Zealand (2021) Recognized Seasonal Employer (RSE) Scheme Research.

https://www.immigration.govt.nz/about-us/research-and-statistics/research-reports/re cognised-seasonal-employer-rse-scheme

Radio New Zealand (2020). Samoa Losing Skilled Labour to Seasonal Worker Schemes-Business Group. Radio New Zealand. https://www.rnz.co.nz/international/pacific-news/407317/samoa-losing-skilled-labourto-seasonal-worker-schemes-business-group

Ramsamy, S., Krishnan, R., Bedford, R., \& Bedford C. (2008). The Recognised Seasonal Employer Policy: Seeking the Elusive Triple Wins for Development through International Migration. Pacific Economic Bulletin, 23, 171-186. 